\title{
Experimental Analysis on FRP Strengthened Autoclaved Aerated Concrete Panels
}

\author{
Bo WANG ${ }^{1,2, *}$, Xin-Li KONG ${ }^{1,2}$, Mei-Rong JIANG ${ }^{1,2}$, Hao WU ${ }^{1,2}$ and Yi-Shun \\ CHEN $^{1,2}$
}

\author{
${ }^{1}$ College of Defense Engineering, PLA University of Science and Technology \\ ${ }^{2}$ State Key Laboratory for Disaster Prevention \& ${ }^{1}$ Mitigation of Explosion \& Impact, PLA \\ University of Science and Technology, Nanjing, 210007, China
}

*wbo5503@163.com

Keywords: FRP, AAC, Panel, Debonding.

\begin{abstract}
The structural behavior of fiber-reinforced polymer (FRP) reinforced autoclaved aerated concrete (AAC) panels has been investigated. Four FRP/AAC panels and two non FRP AAC panels were prepared for testing. The panels were tested under four-point bending test to investigate their strength and displacement of mid-span responses using a bending pressure testing machine. Experimental results showed that FRP laminates increased the bearing capacity of AAC panels. A theoretical analysis was conducted to predict the strength of the FRP/AAC member, and the results found were in good accordance with the experimental results.
\end{abstract}

\section{Introduction}

Because of their high stiffness and strength, fiber reinforced polymers (FRPs) have been widely applied in civil engineering. It has been proved that FRP strengthening method is effective to enhance the load carrying capacity of masonry constructions. Currently, reinforced AAC elements have been widely used in panelized constructions, such as roof panels, floor decks, exterior or partitional wall panels, etc. Many studies on FRPs reinforced AAC elements have been conducted [1-3].

Contrast to normal concrete panels, the failure mechanics of FRP reinforced AAC (FRP/AAC) panels is complex, which is not completely solved [4]. Shear bearing capacity and failure mode of FRP reinforced AAC panels are affected by many factors, studies on which are relatively less than the studies on bending failure. Because of the complexity of the problem and the research results are relatively limited, puts forward a practical and reliable design model is more difficult. Five FRP/AAC panels and two plain AAC panels have been investigated. As observed in the experiment, the failure modes of FRP/AAC panels in experiment were shear damage. The damage course of the panels using varieties of wrapping methods was analyzed.

\section{Objectives}

Table 1 lists the mechanical properties of the AAC panels used as the base material. The mechanical properties of carbon fibers sheet, basalt fibers sheet, and epoxy resin used in this research are listed in Table 2.

In order to investigate the panels applied in practical engineering, the AAC external wall panels produced by Nanjing Asahi New Building Materials Co., Ltd. were chosen as the specimen. Fig. 1 shows the reinforcement drawing of these AAC panels. Each AAC panel was measured $1200 \mathrm{~mm} \times 600 \mathrm{~mm} \times 100 \mathrm{~mm}$, and 18 steel bars within it ( 9 bars in each row). The diameter of each bar is $5 \mathrm{~mm}$. 
Table 1. Mechanical Properties of the AAC Panels

\begin{tabular}{|c|c|c|c|c|}
\hline \multirow{2}{*}{$\begin{array}{c}\text { Compressive } \\
\text { Strength }\end{array}$} & \multirow{2}{*}{$\begin{array}{l}\text { Tensile } \\
\text { Strength }\end{array}$} & \multirow{2}{*}{$\begin{array}{l}\text { Shear } \\
\text { Strength }\end{array}$} & \multicolumn{2}{|c|}{ Elasticity Modu Densit } \\
\hline & & & lus & $\mathrm{y}$ \\
\hline $4 \mathrm{MPa}$ & $0.5 \mathrm{MPa}$ & $0.5 \mathrm{MPa}$ & $1.8 \mathrm{GPa}$ & $\begin{array}{c}525 \mathrm{~kg} / \\
\mathrm{m}^{3}\end{array}$ \\
\hline
\end{tabular}

Table 2. Mechanical Properties of epoxy resin FRPs composite

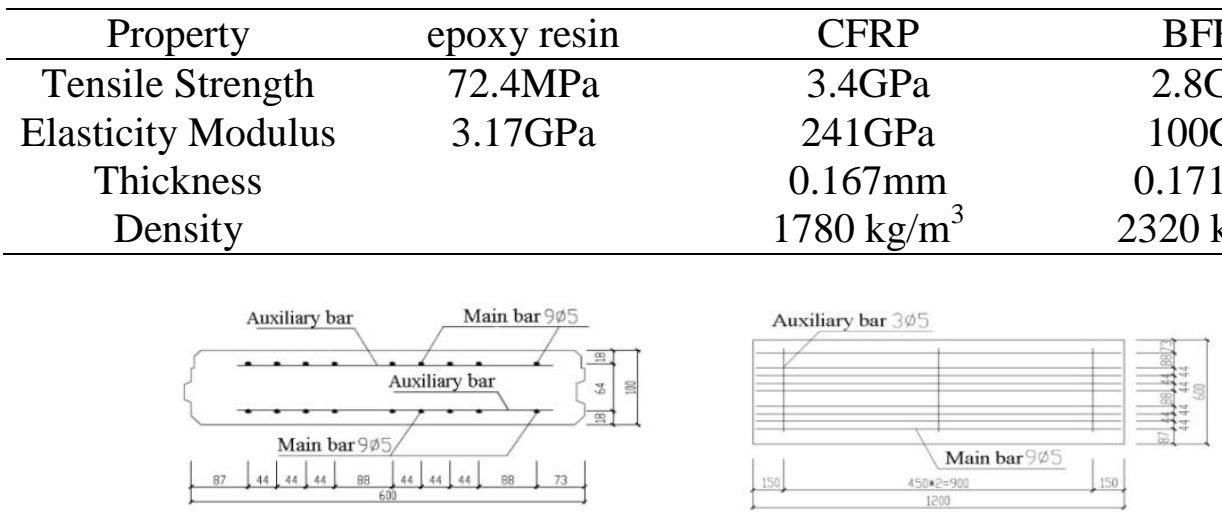

Fig. 1 Reinforcement Drawing of AAC panels

The main objectives for this research were (1) to assess the AAC panels' performance under a four-point bending test and discuss results in terms of load, mid-span displacement, ultimate strength, and failure mode; (2) to compare four types of FRP wrapping AAC panels: unidirectional CFRP lamina, bidirectional CFRP lamina, unidirectional BFRP lamina, and bidirectional BFRP lamina; (3) to propose and validate a theoretical formulas appropriated for analyzing FRP/AAC panels.

\section{Experimental Researches}

\section{Panel Prototypes}

In this research, four types of AAC panels have been made: (1) two panels wrapped by unidirectional FRP laminate for Flexural Reinforcement (F3 BFRP, F5 CFRP); (2) two panels wrapped by bidirectional FRP for Flexural and Shear Reinforcement (F4 BFRP, F6 CFRP); Besides, two plain AAC panels without FRP wrapping (F1, F2) were prepared for comparison.

All of the testing panels were prepared through labor intensive hand lay-up process. The flexural reinforcement FRP wrapping panels (F3, F5) were sandwiched by top and bottom unidirectional fiber lamina. While the flexural and shear reinforcement FRP wrapping panels (F4, F6) were wrapped by top and bottom fiber lamina for flexural reinforcement and then wrapped by lamina for shear reinforcement. The wrapping methods are shown in Fig. 2.

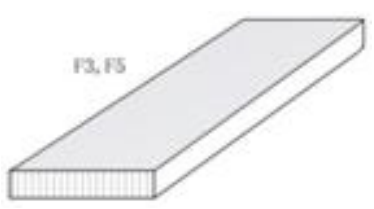

(a)

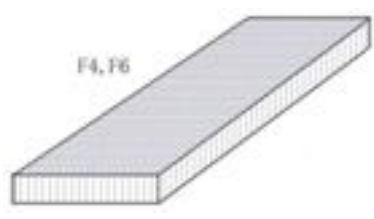

(b)

Fig. 2 Schematic diagrams for the panels used in the experimental work; (a) unidirectional FRP wrapping, (b) bidirectional FRP wrapping. 
Method

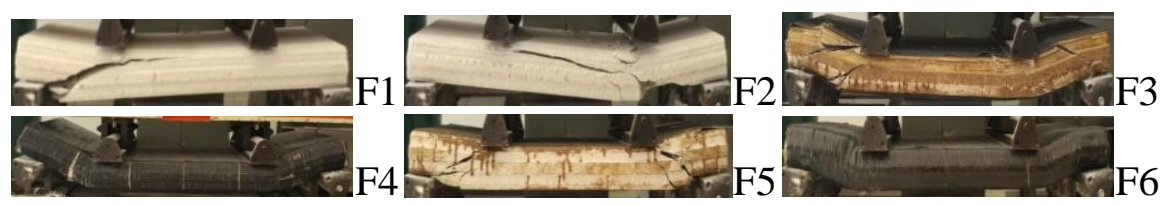

Fig. 3. Photos of Specimen's Failure

The four-point bend tests were used to investigate the structural response of the specimen. $50 \mathrm{kN}$ WYW-50 bending machine made by Hualong Test Instrument Company was used in the test. An electronic displacement gauge was placed at the mid-span of the panel to automatically record the mid-span displacement by computer. The four-point test is shown in Fig. 3. The span length of specimen is $1100 \mathrm{~mm}$. The space of the two loading point is $550 \mathrm{~mm}$, which is at the quarter point of the specimen. The testing environment is $25^{\circ} \mathrm{C}$ and with humidity $70 \%$.

\section{Experimental Results and Discussion}

As shown in Fig. 3, all of the panels were broken (underwent failure) due to shear. In general, the failure mode of the specimen was the sudden cracking of AAC in shear zone. As observed in the test, the plain AAC panels without FRP wrapping (F1, F2) failed immediately at one maximum shear zone. In order to compare values of the specimen, the average ultimate load of F1 and F2, $33.96 \mathrm{kN}$, was used to be the standard ultimate load of plain AAC panel.

As for the unidirectional FRP wrapping panels (F3, F5), the failure mode was the cracking of AAC in shear zone followed by end debonding of FRP. As shown in Fig. 4(a, b), two main steps could be observed: Firstly, the wrinkling of FRP in compression occurred at load of $10.47 \mathrm{kN}$, and 24.11 respectively. Secondly, followed at once by FRP end debonding, the AAC panel cracked at the maximum shear at $40.87 \mathrm{kN}$, and 42.67 respectively. The broken of the bonding layer between $\mathrm{AAC}$ and FRP is the reason for failure.

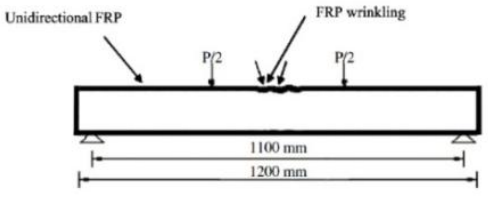

(a) Step 1, Wrinkling of FRP

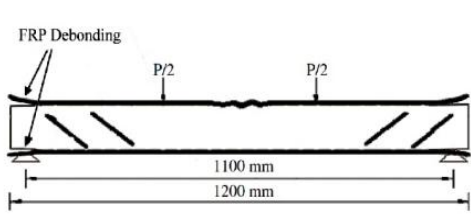

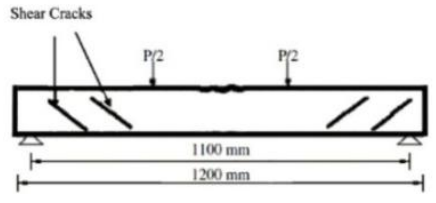

(b) Step 2, Shear cracks of AAC

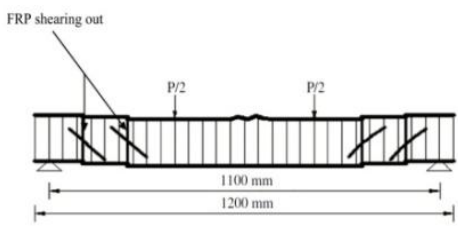

(c, d) Step 3, FRP debonding

Fig. 4. Schematic Diagram for Failure Steps 
Table 3. Testing results for the specimen

\begin{tabular}{|c|c|c|c|c|}
\hline $\begin{array}{c}\text { Panel } \\
\text { No. }\end{array}$ & $\begin{array}{c}\text { Ultimate } \\
\text { Load }(\mathrm{kN})\end{array}$ & $\begin{array}{c}\text { Final mid- } \\
\text { deflection }(\mathrm{mm})\end{array}$ & FRP wrapping & $\begin{array}{c}\text { Load Bearing } \\
\text { Enhancing Ratio }\end{array}$ \\
\hline $\mathrm{F} 1$ & 34.92 & 6.02 & No FRP wrapping & $2.83 \%$ \\
\hline $\mathrm{F} 2$ & 32.99 & 5.63 & No FRP wrapping & $-2.86 \%$ \\
\hline F3 & 40.87 & 7.15 & $\begin{array}{c}\text { unidirectional } \\
\text { BFRP }\end{array}$ & $20.3 \%$ \\
\hline F4 & 44.08 & 9.12 & bidirectional BFRP & $29.8 \%$ \\
\hline F5 & 42.67 & 7.61 & $\begin{array}{c}\text { unidirectional } \\
\text { CFRP }\end{array}$ & $25.6 \%$ \\
\hline F6 & above 50 & - & bidirectional CFRP & Over $47.2 \%$ \\
\hline
\end{tabular}

As for the bidirectional FRP wrapping panels (F4, F6), the ultimate failure mode was the AAC shear cracking followed by FRP shearing out. The schematic diagram for FRP shearing out was shown in Fig. 4(c, d). As observed, there was an obvious increase of deflection at mid-span. The shearing out of FRP occurred nearly the same time as the cracks of AAC. Furthermore, the failure of FRP/AAC panels is an instant failure rather than a progressive one. But the bearing capacity remained at a high level during the expanding of the deflection of the panels ranging from $44.08 \mathrm{kN}$ to over $50 \mathrm{kN}$. As the load of F6 was beyond the measuring range of the instrument, the mid-span displacement of F6 was failed to be measured.

The testing results of the specimen presented in Table 3. Because of the strengthening of FRPS, the load bearing capacity and the toughness of the FRP AAC panels have been increased. The load bearing capacity enhancing of unidirectional FRP strengthening panels is less than that of bidirectional FRP strengthening panels. The latter ones are 29.8\% (bidirectional BFRP), and over $47.2 \%$ (bidirectional CFRP) respectively. While the former ones increased ductility of the panels.

\section{Analyses}

The current calculating formula for ultimate bearing capacity of FRP strengthening panel is under the assumption as: tensile failure of FRP, or pressure crushing of concrete. Stripping failure of FRP is the common failure of FRP strengthening AAC, but the current formula is not applicable. The expected failure mode is the FRP tensile failure or concrete pressure crushing after reinforcement yielding.

\section{Tensile Shear Damage}

According to sandwich theory, the shearing force of FRP/AAC panel is,

$$
\mathrm{V}=\mathrm{V}_{\mathrm{c}}+\mathrm{V}_{\mathrm{frp}}+\mathrm{V}_{\mathrm{s}}
$$

Where $V_{c}, V_{\text {frp }}$, Vs are the shear provided by concrete, FRP, and steel reinforcement, respectively. Proposed by Chen \& Teng, [5]

$$
\mathrm{V}_{\text {frp }}=2 \mathrm{~V}_{\text {frp, }} \mathrm{e}_{\mathrm{frp}} \mathrm{W}_{\text {frp }}\left[\mathrm{h}_{\text {frp,e }}(\sin \beta+\cos \beta)\right] / \mathrm{s}_{\text {frp }}
$$

$\mathrm{f}_{\text {frp, }}$ is average stress in crossing area of FRP and shearing crack, $t_{\text {frp }}$ is the thickness of FRP, $w_{\text {frp }}$ is the width of FRP stripe, $s_{\text {frp }}$ is the FRP stripes' spacing, $\beta$ is the horizontal angle of FRP fiber, $\mathrm{h}_{\mathrm{frp}, \mathrm{e}}$ is effective height of FRP stripes.

As for plain AAC panel, shear provided by AAC is [6] 


$$
\mathrm{Vc}=0.7 \mathrm{f}_{\mathrm{t}} \mathrm{bh}
$$

Shear provided by AAC was $17.33 \mathrm{kN}$.

For FRP strengthened AAC panel, the crack of AAC occurred before the shear failure of the sandwich panels. Then the presence of high-strength FRP materials on the tension side of concrete beams leads to an increase in tensile and shear stresses in the concrete cover within the shear span. As this concrete layer is not confined by internal steel shear reinforcement, the tensile force from the bonded FRP reinforcement cannot be transferred to the internal concrete core and, as a result, the beams fail when the shear capacity of the equivalent unreinforced concrete element is exceeded by the applied loading. [7]. In the inelastic zone, AAC becomes crushed and the strength contribution of the AAC to the FRP/AAC composite panel is not significant. Therefore, in nonlinear range the contribution of $\mathrm{AAC}$ in compressive forces is considered none. [8]

So the equilibrium equation becomes

$$
\mathrm{V}=\mathrm{V}_{\mathrm{frp}}
$$

Shear provided by CFRP is 26981.9. Shear provided by BFRP is 22752.6.

\section{Plate-end Debonding Failure}

Interface debonding between concrete and FRP is the main failure mode of FRP strengthened structures. Ultimate shear strength and normal stress both occurred at the end of beam, that's why end stripping damage occurs [9]. According to Oehlers model, the shearing force at the end of the panel is given by [10]:

$$
\mathrm{V}_{\mathrm{db}, \text { end }}=\eta[1.4-\mathrm{d} / 2000] \mathrm{b}_{\mathrm{c}} \mathrm{d}\left[\rho_{\mathrm{s}} \mathrm{f}_{\mathrm{c}}{ }^{\prime}\right]^{1 / 3}
$$

Where, $d=$ effective depth of section, $b_{c}=$ width of section, $\rho_{s}=$ ratio of tensile steel reinforcement, $\mathrm{f}_{\mathrm{c}}{ }^{\prime}=$ cylinder compressive strength of concrete.

As for shear damage coefficient $\eta$, Smith and Teng proposed 1.4, based on experimental data ${ }^{[11]}$. The suggested $\eta$ for AAC is 1.3 , then

$$
\mathrm{V}_{\mathrm{db}, \text { end }}=1.3[1.4-\mathrm{d} / 2000] \mathrm{b}_{\mathrm{c}} \mathrm{d}\left[\rho_{\mathrm{s}} \mathrm{f}_{\mathrm{c}}{ }^{\prime}\right]^{1 / 3}
$$

\section{Validation of the Prediction}

As analyzed above, the failure modes of plain AAC panel and bidirectional FRP wrapping panels are tensile shear damage. The nominal shear strength for them can be calculated by Chen \& Teng model using Eq. (3) and Eq. (4) respectively. While the failure mode of unidirectional FRP wrapping panels is plate-end debonding failure. Eq. (6) can be used to predict the shear strength, which is based on revised Oehlers model.

Table 4 summarizes the nominal and experimental shear strength of specimen. The difference between the nominal and experimental shear strength is $0.8 \%$ and $4.8 \%$ for plain AAC panels, $3.3 \%$ and $7.8 \%$ for unidirectional FRP wrapping AAC panels, $3.1 \%$ and $7.3 \%$ for bidirectional FRP wrapping AAC panels. The close convergence illustrates the accuracy of the proposed model. 
Table4. Comparison between experimental and calculated value

\begin{tabular}{|c|c|c|c|c|c|}
\hline Panel & $\begin{array}{c}\text { FRP } \\
\text { wrapping }\end{array}$ & $\begin{array}{c}\text { Experimental } \\
\text { shear strength } \\
(\mathrm{kN})\end{array}$ & Failure Model & $\begin{array}{l}\text { Nominal shear } \\
\text { strength }(\mathrm{kN})\end{array}$ & Difference \\
\hline $\mathrm{F} 1$ & $\begin{array}{c}\text { No FRP } \\
\text { wrapping }\end{array}$ & 17.46 & $\begin{array}{c}\text { Tensile shear } \\
\text { damage of AAC }\end{array}$ & 17.33 & $0.8 \%$ \\
\hline $\mathrm{F} 2$ & $\begin{array}{l}\text { No FRP } \\
\text { wrapping }\end{array}$ & 16.50 & $\begin{array}{c}\text { Tensile shear } \\
\text { damage of AAC }\end{array}$ & 17.33 & $4.8 \%$ \\
\hline F3 & $\begin{array}{l}\text { unidirection } \\
\text { al BFRP }\end{array}$ & 20.44 & $\begin{array}{c}\text { Plate-end } \\
\text { debonding failure }\end{array}$ & 19.79 & $3.3 \%$ \\
\hline $\mathrm{F} 4$ & $\begin{array}{l}\text { bidirectiona } \\
1 \mathrm{BFRP}\end{array}$ & 22.04 & $\begin{array}{l}\text { Tensile shear } \\
\text { failure of FRP }\end{array}$ & 22.75 & $3.1 \%$ \\
\hline F5 & $\begin{array}{l}\text { unidirection } \\
\text { al CFRP }\end{array}$ & 21.34 & $\begin{array}{c}\text { Plate-end } \\
\text { debonding failure }\end{array}$ & 19.79 & $7.8 \%$ \\
\hline F6 & $\begin{array}{c}\text { bidirectiona } \\
1 \mathrm{CFRP}\end{array}$ & Over 25 & $\begin{array}{l}\text { Tensile shear } \\
\text { failure of FRP }\end{array}$ & 26.98 & $\begin{array}{l}\text { About } \\
7.3 \%\end{array}$ \\
\hline
\end{tabular}

\section{Conclusions}

(1) Since the low strength of AAC, the modes of failure for all of the panels are brittle shear damage. While FRP wraps enhance the bearing capacity of AAC by $20.3 \%$ to $47.2 \%$ over the unwrapped panels.

(2) For unidirectional FRP wraps, the failure mode is tensile shear failure of FRP. The formula proposed by Chen $\&$ Teng can be used to predict the ultimate bearing capacity.

(3) The failure mode of bidirectional FRP wrapping AAC panels is plate-end debonding failure. Oehlers model is revised and proposed to calculate the nominal bearing capacity for FRP/AAC panels. The clear convergence between the nominal and the experimental values emphasizes the validity of the equations proposed for obtaining the shear capacities for FRP/AAC panels.

\section{Acknowledgments}

Supports from National Science-Technology Support Plan Projects (Grant No.2014BAB15B01-02), National Natural Science Foundation of China (Grant No. 51308541), Research Fund of National Defense Engineering (Grant No. KYFYZXJK1202) are gratefully acknowledged.

\section{References}

[1] D'Ambrisi, A., Focacci, F., Luciano, R., Luciano, R., Alecci, V. and Stefano, M. D.(2015), "Carbon-FRCM materials for structural upgrade of masonry arch road bridges", Compos Part BEng, 75, 355-366.

[2] Su, L., Li, X. and Wang, Y. (2016), "Experimental study and modeling of CFRP-confined damaged and undamaged square RC columns under cyclic loading", Steel Comp. Struct., 21(2), 411-427.

[3] Bansal, P. P., Sharma, R. and Mehta, A. (2016), "Retrofitting of RC girders using pre-stressed CFRP sheets", Struct. Eng. Mech., 20(4), 833-849.

[4] Dembowski J. A Study of the material properties and structural behavior of Plain and Reinforced AAC components. M.S. thesis. CCEE Department, University of Alabama at Birmingham; 2001.

[5] Chen, J.F. and Teng, J.G. (2003), "Shear capacity of FRP strengthened RC beams: fibre reinforced polymer rupture", Journal of Structural Engineering, ASCE, Vol. 129, No. 5, pp.615-625. 
[6] GB50010-2010 Code for design of concrete structures (2011), National standard of the People's Republic of China; Beijing, China.

[7] Ninoslav Pes`ic'*, Kypros Pilakoutas, "Concrete beams with externally bonded flexural FRPreinforcement: analytical investigation of debonding failure", Composites: Part B 34 (2003) 327338.

[8] Mohammed A. Mousa_, Nasim Uddin, (2009), "Experimental and analytical study of carbon fiber-reinforced polymer (FRP)/autoclaved aerated concrete (AAC) sandwich panels", Engineering Structures, 31 (2009), pp. 2337-2344.

[9] Smith, S.T. and Teng, J.G. (2001), "Interfacial stresses in plated RC beams", Engineering Structures, Vol. 23, No.7, pp.857-871.

[10] J. G. Teng, J. F. Chen, S. T. Smith , L. Lam, (2005), "FRP-Strengthened RC Structures”, pp. 56-77, John Wiley \& Sons, Ltd, Chester, England.

[11] Smith, S.T. and Teng, J.G. (2002), "FRP-strengthened RC beams- II : Assessment of debonding strengthen models", Engineering Structures, Vol. 24, No.4, pp.397-417. 